\title{
Nuclear factor erythroid 2-related factor 2-antioxidant activation through the action of ataxia telangiectasia-mutated serine/threonine kinase is essential to counteract oxidative stress in bovine mammary epithelial cells
}

\author{
Y. F. Ma, ${ }^{* 1}$ Z. H. Wu, ${ }^{*} \dagger^{1}$ M. Gao,${ }^{* 2}$ and J. J. Loor $\ddagger^{2}$ \\ *Institute of Animal Nutrition and Feed, Inner Mongolia Academy of Agriculture and Animal Husbandry Sciences, Huhhot 010031, P. R. China \\ †College of Animal Science, Inner Mongolia Agricultural University, Hohhot 010018, P. R. China \\ ‡Department of Animal Sciences, Division of Nutritional Sciences, University of Illinois, Urbana 61801
}

\begin{abstract}
Nuclear factor (erythroid-derived 2)-like factor 2 (NFE2L2, formerly Nrf2) is a transcription factor that binds to the antioxidant response element (ARE) in the upstream promoter region of various antioxidantresponsive genes. Hence, at least in nonruminants, the NFE2L2-ARE signaling pathway plays an important role in the cellular antioxidant defense system. Whether oxidative stress in bovine mammary epithelial cells alters NFE2L2 or the NFE2L2-ARE pathway is unclear. Therefore, the objective of this study was to examine the response in NFE2L2- and NFE2L2-ARErelated components in bovine mammary epithelial cells (BMEC) under oxidative stress. An in silico analysis to identify potential phosphorylation sites on NFE2L2 and the protein kinases was performed with Netphos 3.1 (http://www.cbs.dtu.dk/services/NetPhos/) and Scansite (http://scansite.mit.edu) software. Isolated BMEC were exposed to $\mathrm{H}_{2} \mathrm{O}_{2}(600 \mu M)$ for $6 \mathrm{~h}$ to induce oxidative stress. In silico analysis revealed ataxia telangiectasia-mutated (ATM) serine/threonine kinase as a key kinase responsible for the phosphorylation of NFE2L2. Thus, after the $6 \mathrm{~h}$ incubation with $\mathrm{H}_{2} \mathrm{O}_{2}$, BMEC were transiently transfected with ATM-small interfering RNA (siRNA) 1, 2, or 3. Compared with the control, transfection with ATM-siRNA3 resulted in proliferation rates that were 60.7 and $36.2 \%$ lower with or without $\mathrm{H}_{2} \mathrm{O}_{2}$. In addition, production of reactive oxygen species and malondialdehyde increased markedly, but activities of superoxide dismutase, glutathione peroxidase, catalase, and glutathione-S-transferase decreased markedly in transfected cells without or with
\end{abstract}

Received October 6, 2017.

Accepted February 20, 2018.

${ }^{1}$ These authors contributed equally.

${ }^{2}$ Corresponding authors: gmyh1588@126.com and jloor@illinois.edu
$\mathrm{H}_{2} \mathrm{O}_{2}$ compared with the control. Transfected cells had markedly lower protein and mRNA expression of NFE2L2 without or with $\mathrm{H}_{2} \mathrm{O}_{2}$ compared with the control. In addition, fluorescent activity of the ARE in transfected BMEC indicated that NFE2L2-driven transcriptional activation decreased under oxidative stress. Overall, results indicate that ATM is a physiologically relevant NFE2L2 kinase. Furthermore, inhibition of ATM activity can cause marked alterations in oxidative stress leading to cell death as a result of diminished capacity of BMEC to cope with $\mathrm{H}_{2} \mathrm{O}_{2}$-induced cytotoxicity. The relevance of this kinase in vivo merits further study.

Key words: nuclear factor (erythroid-derived 2)like factor 2-antioxidant response element pathways, ataxia telangiectasia-mutated serine/threonine kinase, oxidative stress, bovine mammary epithelial cell

\section{INTRODUCTION}

Due to the constant challenge by environmental (xenobiotics, drugs, and UV light) and endogenous [reactive oxygen species (ROS), hydroperoxides] stressors, cells are major targets of oxidative stress (Klaunig et al., 2010). These environmental and endogenous stressors or their metabolites can directly and indirectly drive the production of ROS. The ROS are produced continuously as natural by-products of the normal metabolism of oxygen and play important roles in redox balance (Lee and Griendling, 2008). For example, intracellular lipid peroxidation leads to production of $\mathrm{H}_{2} \mathrm{O}_{2}$ and ROS, which in culture can decrease the number and viability of bovine mammary epithelial cells (BMEC, MACT; Jin et al., 2016), rodent cells (Burdon, 1995; Mori et al., 2004), and human breast adenocarcinoma cells (MCF-7; Dasari et al., 2006). Although the mechanisms associated with injury of BMEC are not well known, increasing evidence indicates that oxidative stress caused by $\mathrm{H}_{2} \mathrm{O}_{2}$ is a key factor (Jin et al., 2016). 
In nonruminants, upon binding to the antioxidant response element (ARE) sequence, the redox sensitive transcription factor nuclear factor (erythroid-derived 2)-like factor 2 (NFE2L2, formerly Nrf2) regulates mRNA expression of cellular defense enzymes and certain antioxidant proteins (Kensler et al., 2007; Niture et al., 2014). Extensive work in nonruminant cells has revealed that the NFE2L2-ARE signaling pathway is one of the main defense mechanisms whereby cells can handle $\mathrm{H}_{2} \mathrm{O}_{2}$-induced oxidative damage (Kensler et al., 2007). Under physiological conditions and states of low oxidative stress, NFE2L2 is retained in the cytosol via the actin binding protein Kelch-like epichlorohydrinassociated protein (Keap1), which negatively regulates NFE2L2 by targeting it for ubiquitination and proteasomal degradation (Itoh et al., 1999; Hayes and McMahon, 2001). When cells are under oxidative stress, NFE2L2 is rapidly released from Keap1; it then translocates to the nucleus where it binds to ARE and induces the phase II detoxifying enzyme genes (Dinkova-Kostova et al., 2002).

Oxidative and electrophilic stresses induce alterations in the NFE2L2-Keap1 complex, preventing proteasomal degradation and enhancing NFE2L2/ ARE-linked gene transcription (Tong et al., 2006). Work with nonruminant cells indicated that phase II detoxifying enzymes responsive to NFE2L2 activation include heme oxygenase-1 (HMOX1, formerly HO-1), NADH quinone oxidoreductase 1 (NQO1), glutamate-cysteine ligase catalytic subunit (GCLC), glutamyl cystine ligase modulatory subunit (GCLM), superoxide dismutase (SOD), glutathione peroxidase (GSH-Px), catalase (CAT), glutathione-S-transferase (GST), and antioxidative stress proteins (Itoh et al., 1999; Zhu et al., 2005). Although data in bovine cells are scarce, a recent study with BMEC indicated that the NFE2L2-ARE signaling pathway and its downstream antioxidant enzymes HMOX1, NQO1, GCLC, and GCLM have a crucial role in the ability of those cells to cope with $\mathrm{H}_{2} \mathrm{O}_{2}$-induced oxidative stress (Jin et al., 2016). However, the mechanisms that prevent BMEC from dealing with $\mathrm{H}_{2} \mathrm{O}_{2}$-induced oxidative stress and the reason for low NFE2L2 activity under oxidative conditions are largely unknown.

We hypothesized that dysfunction in the NFE2L2ARE signaling pathway in BMEC may result in increased sensitivity to $\mathrm{H}_{2} \mathrm{O}_{2}$-induced oxidative insults. Therefore, the aim of the present study was to determine the role of protein kinases on the phosphorylation status of NFE2L2 and subsequent alterations in mRNA expression of target genes in cultured BMEC under oxidative stress.

\section{MATERIALS AND METHODS}

\section{Cell Culture and Treatment}

Mammary tissue was harvested from five 4-yr-old late-lactation dairy cows from a local slaughterhouse (Hohhot, China). The midpoint area of left rear side of the udder was clipped and surgically scrubbed. Approximately $150 \mathrm{mg}$ of fresh tissue from each cow was removed and placed in sterilized tubes containing icecold Dulbecco's PBS (DPBS, Sigma, St. Louis, MO) and immediately transported to the laboratory. The samples were washed with DPBS 3 times and cut into 1 $\mathrm{mm}^{3}$ pieces. Tissue was transferred with tweezers onto clean, sterile, plastic cell culture dishes (Corning Inc., Corning, NY). The culture dishes were maintained in a humidified incubator at $37^{\circ} \mathrm{C}$ in an atmosphere of $5 \%$ $\mathrm{CO}_{2}$ and $95 \%$ air. After $4 \mathrm{~h}, 5 \mathrm{~mL}$ of basal medium was added into the culture. The basal medium was replaced with fresh medium every 24 or $48 \mathrm{~h}$ until the cells were thoroughly distributed across the bottom of the dish. Subsequently, epithelial cells were enriched by selective detachment with trypsinization using $0.25 \%$ trypsin (Gibco, Grand Island, NY). After 3 min of trypsinization, detached fibroblast was removed by washing with DPBS. The epithelial cells attached to the dish surface were allowed to grow by addition of fresh medium. The BMEC were continuously purified using the same method. The purified BMEC were seeded at a density of $5 \times 10^{5}$ cells in culture flasks, and continuously subcultured up to 60 passages. For cryopreservation, $1 \times$ $10^{6}$ cells $/ \mathrm{mL}$ was suspended in freezing medium. To establish oxidative stress, $600 \mu M \mathrm{H}_{2} \mathrm{O}_{2}$ was applied to the BMEC.

Basal medium was composed of $85.74 \mathrm{~mL}$ of DMEM/ F12 (12400-024, Gibco) and $10 \mathrm{~mL}$ of $10 \%$ (vol/vol) fetal bovine serum (FBS, Gibco). The lactogenic medium was developed by supplementing the basal medium with $0.5 \mathrm{~mL}$ of $0.5 \%$ insulin and transferrin solution (Gibco), $2 \mathrm{~mL}$ of penicillin streptomycin (Gibco), 100 $\mu \mathrm{L}$ of $1 \mu \mathrm{g} / \mathrm{mL}$ hydrocortisone (Gibco), $100 \mu \mathrm{L}$ of 2.5 $\mu \mathrm{g} / \mathrm{mL}$ amphotericin B (Gibco), $10 \mu \mathrm{L}$ of $10 \mathrm{ng} / \mathrm{mL}$ epidermal growth factor (Gibco), $50 \mu \mathrm{L}$ of $5 \mu \mathrm{g} / \mathrm{mL}$ prolactin, and $1.5 \mathrm{~mL}$ of glutamine (Gibco).

\section{Transient Transfection of Ataxia Telangiectasia-Mutated Gene}

Small interfering RNA (siRNA; Beyotime Institute of Biotechnology, Shanghai, China) was used to silence the $A T M$ gene. In brief, mammary epithelial cells $(2 \times$ $10^{6}$ cells per well for 6 -well plates and $2 \times 10^{5}$ cells per 
well for 96-well plates) were plated into each well and cultured for $24 \mathrm{~h}$. Cells were transfected with ATM-siR$\mathrm{NA}$ at 90 to $95 \%$ confluence using Lipofectamine 2000 transfection reagent (Gibco). After $12 \mathrm{~h}$ of incubation, cells were recovered in normal medium after removal of transfection reagents and were then incubated for an additional $36 \mathrm{~h}$ with or without $\mathrm{H}_{2} \mathrm{O}_{2}$ treatment. Mammary epithelial cells in 6-well plates were harvested 48 $\mathrm{h}$ after transfection for assessing mRNA and protein expression. For the cells cultured in 96-well plates, the culture medium was switched to serum-free, antibioticfree Dulbecco's modified Eagle medium (DMEM) 48 $\mathrm{h}$ after transfection, and the cells were then subjected to $600 \mu M \mathrm{H}_{2} \mathrm{O}_{2}$ for $6 \mathrm{~h}$. This supraphysiologic dose of $\mathrm{H}_{2} \mathrm{O}_{2}$ was selected based on data from our unpublished studies including doses of 0 to $1,000 \mu M$ in which cell proliferation, concentration of ROS, and activity of SOD and GSH-Px were evaluated. The BMEC proliferation rate in the control (no siRNA), scrambled siRNA transfected group with or without $\mathrm{H}_{2} \mathrm{O}_{2}$, ATM-siRNA3 transfected group with or without $\mathrm{H}_{2} \mathrm{O}_{2}$ was measured as described below.

\section{RNA Interference}

Three siRNA specific for ATM (ATM-siRNA1, ATMsiRNA2, and ATM-siRNA3) and a scrambled sequence (scrambled-siRNA) were designed and synthesized (Table 1). Mammary epithelial cells were transfected in antibiotic-free medium following the manufacturer's instructions. Briefly, healthy BMEC were routinely trypsinized and resuspended to $2 \times 10^{6}$ cells $/ \mathrm{mL}$ in normal growth medium without antibiotics, and cells were then set aside at $37^{\circ} \mathrm{C}$. After $24 \mathrm{~h}$, the cells were transfected with ATM-siRNA. After incubation for $5 \mathrm{~min}$ at $37^{\circ} \mathrm{C}$, the siRNA and lipofectamine were mixed, incubated at room temperature for an additional $20 \mathrm{~min}$, and added to each well. The cell suspension that was previously set aside was transferred to the same wells containing the complex $\left(2 \times 10^{6}\right.$ cells per well for 6 -well plates and $2 \times 10^{5}$ cells per well for 96-well plates), and the cell suspension was mixed by gently rocking the plates back and forth. The medium was replaced by fresh medium $12 \mathrm{~h}$ after transfection. The BMEC in 6-well plates were harvested $48 \mathrm{~h}$ after transfection to assess mRNA and protein changes, respectively. At $48 \mathrm{~h}$ after transfection, the culture medium for the BMEC in 96-well plates was switched to serum-free, antibiotic-free DMEM, and the cells were then subjected to $600 \mu M \mathrm{H}_{2} \mathrm{O}_{2}$ for $6 \mathrm{~h}$. The cell proliferation rate of ATM-silenced and control culture was measured. Scrambled transfections (using a nontargeting siRNA) were performed in each experiment.

\section{BMEC Proliferation Rate Assay}

The BMEC proliferation rate was performed using the 3 - $(4, \quad 5$-dimethylthiazol-2-yl)-5-(3-carboxymethoxyphenyl)-2-(4-sulfophenyl)-2H-tetrazolium (MTS) assay kit according to the manufacturer's instruction. Briefly, MTS (20 $\mu \mathrm{L} /$ well, Sigma-Aldrich) was added to each well and incubated for $4 \mathrm{~h}$ at $37^{\circ} \mathrm{C}$. Subsequently, $150 \mu \mathrm{L}$ of dimethyl sulfoxide (DMSO, Sigma-Aldrich) was added to each well and incubated for $10 \mathrm{~min}$ at $37^{\circ} \mathrm{C}$. Last, the absorbance at $490 \mathrm{~nm}$ was determined with a microplate reader (Molecular Devices, Sunnyvale, CA).

\section{Detection of Oxidative Stress Indicators}

The total superoxide dismutase (SOD), glutathione peroxidase (GSH-Px), catalase (CAT), and glutathione-S-transferase (GST) activities, and the malondialdehyde (MDA) production in BMEC were determined using the xanthine oxidase, 5'5-dithio-bis-nitrobenzoic acid display color, ammonium molybdate, and thiobarbituric acid, respectively. In brief, BMEC were washed with PBS and incubated with fresh DMEM containing $50 \mu \mathrm{L}$ of xanthine oxidase, 5'5-dithio-bis-nitrobenzoic acid display color, ammonium molybdate, and thiobarbituric acid, at $37^{\circ} \mathrm{C}$ for $35 \mathrm{~min}$, respectively, then 1 $\times 10^{6}$ cells were harvested and resuspended in PBS. Absorbance was detected at $450 \mathrm{~nm}$ and recorded with a $722 \mathrm{~N}$ spectrophotometer (Scientific Instrument Co. Ltd., Shanghai, China).

\section{Intracellular ROS Detection}

A dichlorofluorescein staining assay was used to detect intracellular ROS. Briefly, BMEC were washed with PBS and incubated with fresh DMEM containing $10 \mu M$ dichlorofluorescein at $37^{\circ} \mathrm{C}$ for $35 \mathrm{~min}$, then 1 $\times 10^{6}$ cells were harvested and resuspended in PBS.

Table 1. Primer sequence for the ataxia telangiectasia-mutated (ATM)-small interfering RNA (siRNA) tested

\begin{tabular}{ll}
\hline Name & Primer sequence $\left(5^{\prime} \rightarrow 3^{\prime}\right.$ orientation $)$ \\
\hline LV-ATM-siRNA1 & \\
Sense & TGAGGAAATACTGGTGTGAAA \\
Antisense & TTTCACACCAGTATTTCCTCA \\
LV-ATM-siRNA2 & \\
Sense & AATCAAGAAAGTGGAGAAGTA \\
Antisense & TACTTCTCCACTTTCTTGATT \\
LV-ATM-siRNA3 & TTCAGAAGATGCTGTGAGAAA \\
Sense & TTTCTCACAGCATCTTCTGAA \\
Antisense & \\
\hline
\end{tabular}


The optical density at $450 \mathrm{~nm}$ was recorded with a microplate reader (Molecular Devices, Sunnyvale, CA).

\section{ARE Fluorescence Activity}

The ARE fluorescence activity was tested in cultured BMEC without or with $\mathrm{H}_{2} \mathrm{O}_{2}$ via an ARE reporter gene according to the manufacturer's instruction (Beyotime Biotechnology). In brief, after the treatment of BMEC with $\mathrm{H}_{2} \mathrm{O}_{2}(600 \mu M)$ for $0,6,12$, and $24 \mathrm{~h}, 50 \mu \mathrm{L}$ of Luciferase Assay Reagent II (LAR II) was added to the BMEC and followed by $10 \mu \mathrm{L}$ of cell lysis buffer. The activity of relative light unit 1 (RLU1) was detected with a Biluciferase reporter gene kit (Beyotime Biotechnology); then $50 \mu \mathrm{L}$ of $50 \times$ Stop and Glo Reagent was added to the BMEC, and the activity of relative light unit 2 (RLU2) was detected again with a Biluciferase reporter gene kit (Beyotime Biotechnology). The RLU1/ RLU2 ratio was used to determine the transfection efficiency of ARE.

\section{Real-Time Reverse-Transcription PCR Analysis}

The reverse-transcription (RT) PCR was performed with SYBR Premix Ex Taq II (TaKaRa, Otsu, Japan) on a Chromo 4 continuous fluorescence detector with a PTC-200 DNA Engine Cycler (Bio-Rad, Hercules, $\mathrm{CA}$ ) to determine the mRNA expression of NFE2L2, $H M O X-1, N Q O-1, G C L C, G C L M$, and $\beta$-actin (internal control). The cycling conditions were as follows: predenaturation at $95^{\circ} \mathrm{C}$ for $30 \mathrm{~s}$ followed by 40 cycles of denaturation at $95^{\circ} \mathrm{C}$ for $5 \mathrm{~s}$, annealing at $60^{\circ} \mathrm{C}$ for 20 $\mathrm{s}$, at $72^{\circ} \mathrm{C}$ for $15 \mathrm{~s}$, and extension at $72^{\circ} \mathrm{C}$ for $30 \mathrm{~s}$. The specificity of the PCR amplification was verified by a dissociation curve analysis. All reactions were run in triplicate. The primers used for RT-PCR are listed in Table 2. Analyses of gene expression data were done using the $2^{-\Delta \Delta \mathrm{Ct}}$ (Livak) method (Livak and Schmittgen, 2001).

\section{Western Blot Analysis}

After treatment, cells were washed twice with $4^{\circ} \mathrm{C}$ PBS (0.01 $M, \mathrm{pH} 7.2-7.3)$ and then lysed with radio immunoprecipitation assay protein lysate (Beyotime
Institute of Biotechnology, Shanghai, China). Total protein was extracted from BMEC using a tissue protein extraction reagent (catalog no. 78510; Thermo Fisher Scientific, Waltham, MA) containing inhibitor cocktail $(100 \times$, catalog no. 78442; Thermo Fisher Scientific). Total protein concentration was determined using the BCA Protein Assay Kit (Sigma, St. Louis, MO). Protein samples were boiled for $20 \mathrm{~min}$ at $100^{\circ} \mathrm{C}$. Fifty micrograms of total protein per lane was resolved by $10 \%$ SDS-PAGE (Bio-Rad) and then transferred from the gel to a polyvinylidene difluoride membrane $(0.45 \mu \mathrm{m}$, Millipore, Billerica, MA). PageRuler Plus Prestained Protein Ladder (Fermentas, Hanover, MD) was used to confirm protein electrophoresis. Membranes were blocked in Tris-buffered saline with Tween (TBST; 50 $\mathrm{m} M$ Tris, $\mathrm{pH}$ 7.6, $150 \mathrm{mM} \mathrm{NaCl}$, and $0.1 \%$ Tween 20), which contained $5 \%$ (wt/vol) nonfat dry milk for $2 \mathrm{~h}$ at room temperature with gentle agitation. The membranes were then incubated in TBST-containing antibodies to ATM (catalog no. ab103970, Abcam, Cambridge, MA), NFE2L2 (catalog no. ab137550, Abcam), HMOX-1 (catalog no. ab13248, Abcam), NQO1 (catalog no. ab 28947, Abcam), GCLC (catalog no. ab 80841, Abcam), and GCLM (catalog no. ab81445, Abcam) with gentle agitation at $4^{\circ} \mathrm{C}$ overnight. After incubating with the primary antibody, the membranes were washed and incubated with horseradish peroxidase-conjugated secondary antibodies (horseradish peroxidase-labeled sheep anti-mouse, 1:50,000; horseradish peroxidaselabeled sheep anti-rabbit, 1:50,000; catalog no. ab6721, Abcam) in TBST for $1 \mathrm{~h}$ at room temperature. The membranes were washed and then incubated with electro-chemi-luminescence reagent (catalog no. 170-5060; Bio-Rad). $\beta$-Actin (catalog no. ab8226; Abcam) were used as internal control. The images were captured using Chemi DOC MP (Bio-Rad). The intensities of the bands were measured with Image-Pro Plus 6.0 software (Media Cybernetics Inc., Rockville, MD).

\section{Statistical Analysis}

All data are expressed as the means \pm standard deviation of the mean from the indicated number of independent experiments performed in triplicate. One-way ANOVA followed by a Student-Newman-Keuls multi-

Table 2. Primers of downstream genes in the Nrf2-antioxidant response element (ARE) signaling pathway

\begin{tabular}{llll}
\hline Gene name & Forward primer $\left(5^{\prime} \rightarrow 3^{\prime}\right)$ & Reverse primer $\left(5^{\prime} \rightarrow 3^{\prime}\right)$ & Accession number \\
\hline NFE2L2 & CCAGCACAACACATACCA & TAGCCGAAGAAACCTCATT & 001011678.2 \\
HMOX-1 & GAACGCAACAAGGAGAAC & CTGGAGTCGCTGAACATAG & 001014912.1 \\
NQO1 & CAACAGACCAGCCAATCA & ACCTCCCATCCTTTCCTC & 001034535.1 \\
GCLC & ATTGGGTGGAGAGTGGAA & ACAGCGGGATGAGAAAGT & 001083674.1 \\
GCLM & CCGATGAAAGAGAAGAAATG & CAACAGGAGGTGAAGCAA & 001038143.1 \\
\hline
\end{tabular}


ple-comparison test was used to determine statistical significance for multiple comparisons, and Student's $t$ test was used for 2 group comparisons. Differences were considered significant at $P<0.05$ and very significant at $P<0.01$. All statistical tests were carried out using SAS 9.0 (SAS Institute Inc., Cary, NC).

\section{RESULTS}

\section{NFE2L2 Phosphorylation}

The NetPhos 3.1 software can predict phosphorylated sites and the identity of the protein kinase (Blom et al., 1999, 2004). Thus, it was used to predict the possible phosphorylation positions on NFE2L2 (Supplemental Figure S1; https://doi.org/10.3168/jds.2017-13954). Results revealed that NFE2L2 is mainly phosphorylated at serine, threonine, and tyrosine sites, and it was also predicted that phosphorylation of NFE2L2 would occur through the kinases ATM serine/threonine kinase (ATM), cyclin-dependent kinase inhibitor, casein kinase II, calmodulin kinase II, DNA-dependent protein kinase, epidermal growth factor receptor, glycogen synthase kinase, insulin receptor, protein kinase $\mathrm{A}$, protein kinase $\mathrm{B}$, protein kinase $\mathrm{C}$, protein kinase $\mathrm{G}$, recombinant streptokinase, tyrosine kinase $\mathrm{C}$, cell division cycle kinase 2, cyclin-dependent kinase 5, and p38 mitogen-activated protein kinase. Subsequently, we used the protein phosphorylation analysis software Scansite (http://scansite.mit.edu) to predict protein kinases that could phosphorylate NFE2L2 (Supplemental Table S1; https://doi.org/10.3168/jds.2017-13954). The highest score was for ATM with threonine 457 (T457) on NFE2L2 as the target for ATM. Thus, this analysis further suggested that ATM may be the physiologically relevant kinase that phosphorylates NFE2L2.

\section{Verification and Screening of ATM-siRNA Interference Fragments}

The BMEC were transfected with different ATMsiRNA interference fragments (ATM-siRNA1, ATMsiRNA2, and ATM-siRNA3) and cultured for $48 \mathrm{~h}$ without (control) or with $\mathrm{H}_{2} \mathrm{O}_{2}$ to induce oxidative stress. Changes in protein and mRNA expression were detected with RT-PCR and Western blot (Figure 1). The results showed that compared with the control group, transfected ATM-siRNA1, ATM-siRNA2, and ATM-siRNA3 reduced protein and mRNA expression of ATM with the best interference efficiency achieved with ATM-siRNA3 $(>94.1 \% ; P<0.01)$. Thus, ATMsiRNA3 was chosen as the interference fragment for subsequent experiments because it was the most efficient and least cytotoxic among the siRNA (Figure 1).

\section{Effect of ATM Expression on the Proliferation Rate of BMEC}

The BMEC were transiently transfected with ATMsiRNA3 and the control scrambled-siRNA with or without exposure to $\mathrm{H}_{2} \mathrm{O}_{2}$. The MTS assay was used to investigate cell proliferation rate after transfection for $48 \mathrm{~h}$ (Figure 2). The results revealed that transfection with scrambled-siRNA and ATM-siRNA3 without $\mathrm{H}_{2} \mathrm{O}_{2}$ decreased $(P<0.05)$ the proliferation rate by 25.8 and $36.2 \%$ compared with the control group. However, under oxidative stress, transfection with scrambledsiRNA and ATM-siRNA3 decreased $(P<0.01)$ the proliferation rate by 52.9 and $60.7 \%$ compared with the control group (Figure 2). No apparent difference in cell proliferation rate was detected between the scrambledsiRNA and ATM-siRNA3 without $\mathrm{H}_{2} \mathrm{O}_{2}$, between the scrambled-siRNA and ATM-siRNA3 with $\mathrm{H}_{2} \mathrm{O}_{2}$, but all of these were significantly lower than the control BMEC. In contrast, $600 \mu M \mathrm{H}_{2} \mathrm{O}_{2}$ caused a significant $(P<0.01)$ reduction in BMEC proliferation rate compared with control BMEC and BMEC without $\mathrm{H}_{2} \mathrm{O}_{2}$. These data further suggested that ATM silencing decreased the ability of BMEC to cope with $\mathrm{H}_{2} \mathrm{O}_{2}$-induced cytotoxicity.

\section{Effect of Regulation of ATM on Antioxidant Enzyme Activities in BMEC}

Activities of SOD, GSH-Px, CAT, and GST and production of ROS and MDA were analyzed after treatment of BMEC with or without $\mathrm{H}_{2} \mathrm{O}_{2}(600 \mu M)$ for $6 \mathrm{~h}$, followed by scrambled-siRNA and ATM-siRNA3 transfection for 48 h. As shown in Figure 3, the transfection

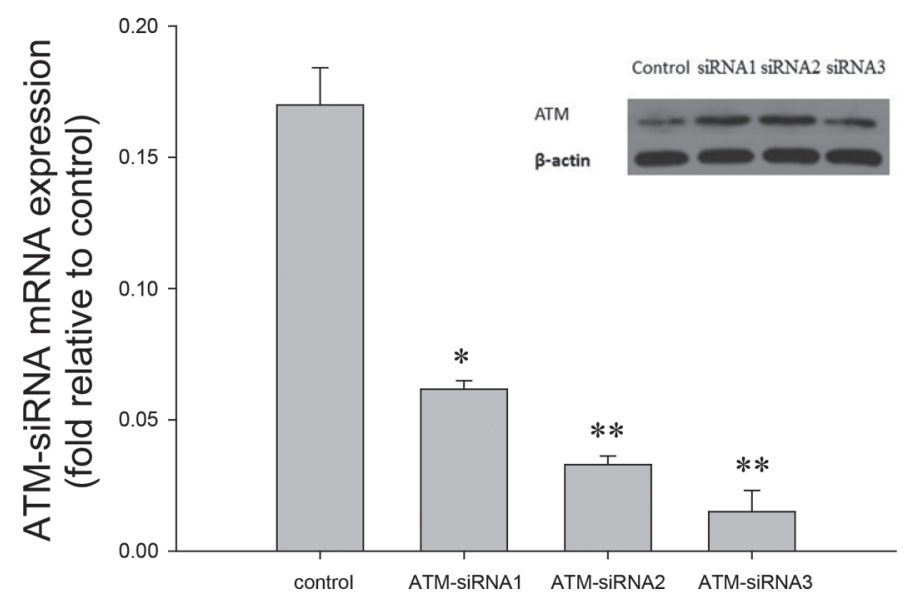

Figure 1. Screening of the efficacy of ataxia telangiectasia-mutated (ATM)-small interfering RNA (siRNA) fragments. The mRNA and protein expression of ATM after siRNA treatment was detected with real-time reverse transcription $\mathrm{RCR}$ and Western Blot. ${ }^{*} P<0.05,{ }^{* *} P$ $<0.01$, differ from untreated cells. Error bars indicate SEM. 
of ATM-siRNA3 without $\mathrm{H}_{2} \mathrm{O}_{2}$ sharply decreased SOD $(P<0.05)$, CAT $(P<0.05)$, GSH-Px $(P<0.05)$, and GST $(P<0.05)$ activity compared with the control. It also increased $\operatorname{ROS}(P<0.01)$ and MDA $(P<0.01)$ production compared with the control. A similar effect was observed in cells transfected with ATM-siRNA3 and incubated with $\mathrm{H}_{2} \mathrm{O}_{2}$. Compared with all groups under normal conditions, the transfection of ATM-siRNA3 and scrambled-siRNA plus addition of $\mathrm{H}_{2} \mathrm{O}_{2}$ decreased SOD $(P<0.05)$, CAT $(P<0.05)$, GSH-Px $(P<0.05)$, and GST $(P<0.01)$ activity. Concentration of ROS $(P$ $<0.05)$ and MDA $(P<0.05)$ also decreased (Figure $3)$. These results further support the hypothesis that ATM serine/threonine kinase is essential for induction of several antioxidant defense enzymes in BMEC under oxidative stress. Results also suggest that the antioxidant enzyme system is impaired in BMEC exposed to supraphysiologic levels of $\mathrm{H}_{2} \mathrm{O}_{2}$.

\section{Effect of Regulating ATM Expression on Downstream Genes in the NFE2L2-ARE Pathway}

To further determine whether ATM has a significant effect on the NFE2L2-ARE pathway in control or ATMsilenced BMEC, and which downstream genes in the NFE2L2-ARE pathway are most affected, we examined the protein and mRNA abundance of NFE2L2 and 4 key phase II detoxifying enzymes of the NFE2L2-ARE pathway: HMOX-1, NQO-1, GCLC, and GCLM. Figures 4 and 5 show the expression of the 4 main phase II detoxifying genes in BMEC after the treatment with and without $600 \mu M \mathrm{H}_{2} \mathrm{O}_{2}$ for $6 \mathrm{~h}$. The RT-PCR and Western blot results in Figures 4 and 5 demonstrate that transfection of ATM-siRNA3 sharply decreased the protein and mRNA expression of NFE2L2 $(P<$ $0.05)$, HMOX-1 $(P<0.05)$, NQO1 $(P<0.05)$, GCLM $(P<0.05)$, and GCLC $(P<0.01)$ under normal conditions compared with the control group, and was lower compared with the transfected scrambled-siRNA $(P<0.05)$. Under oxidative stress, compared with the control group, the transfection of ATM-siRNA3 sharply decreased the protein and mRNA expression of NFE2L2 $(P<0.01)$, HMOX-1 $(P<0.05)$, NQO1 $(P<0.05)$, GCLM $(P<0.05)$, and GCLC $(P<0.01)$, and the protein and mRNA expression of HMOX-1 $(P$ $<0.05)$ was significantly lower than NQO1, GCLM, and GCLC. In all cases, expression was lower compared with the transfection of scrambled-siRNA $(P<0.05)$.

These results suggest that ATM silencing decreased the expression levels of NFE2L2 and all 4 genes in BMEC with or without $\mathrm{H}_{2} \mathrm{O}_{2}$, and revealed that HMOX-1 is the main antioxidant target gene protect-

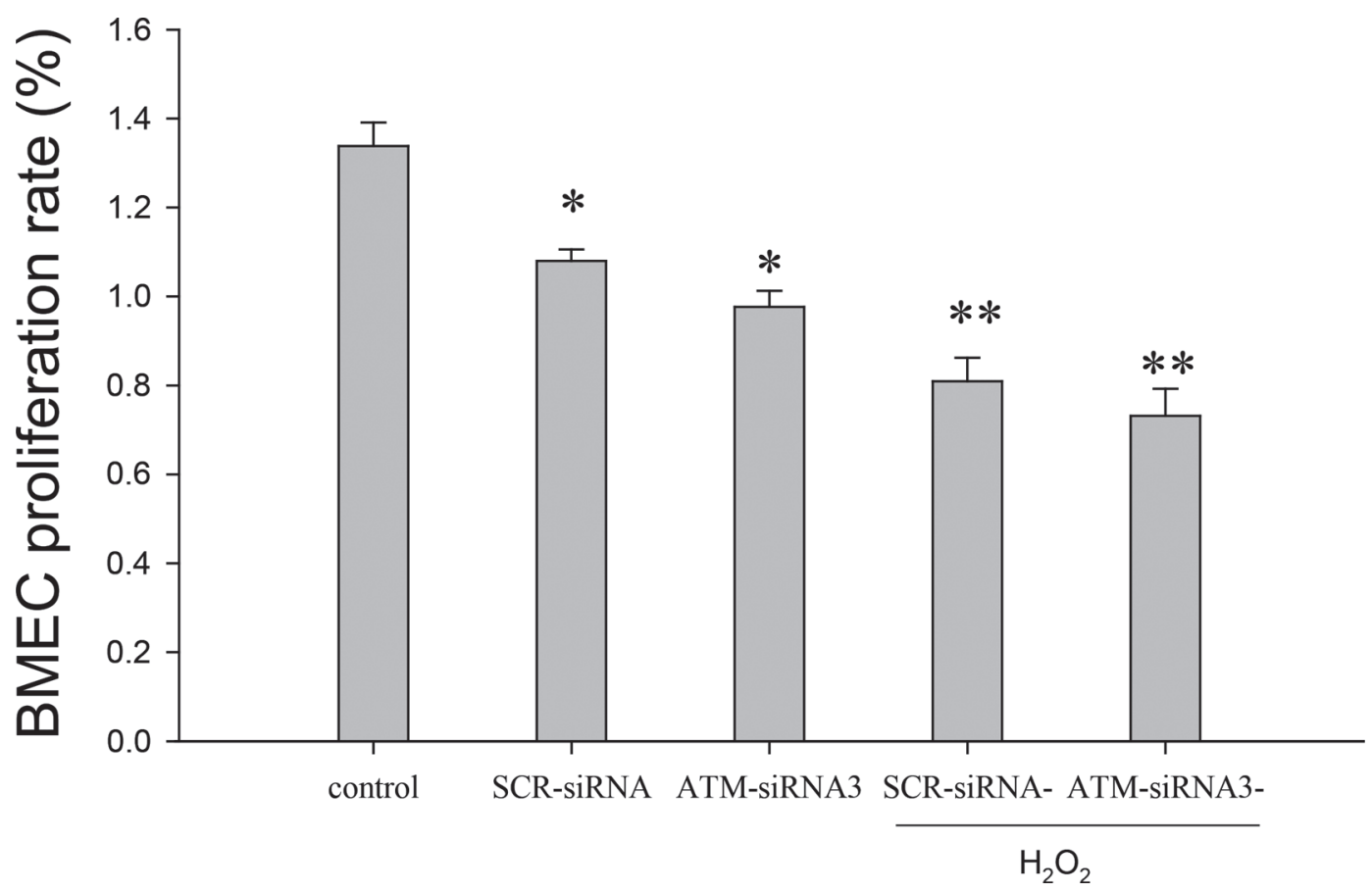

Figure 2. Effects of ataxia telangiectasia-mutated (ATM)-small interfering RNA (siRNA) on the proliferation rate of cultured bovine mammary epithelial cells (BMEC). Cells were cultured with $\mathrm{H}_{2} \mathrm{O}_{2}(600 \mu M)$ for $6 \mathrm{~h}$, followed by scrambled-siRNA and ATM-siRNA3 transfection for $48 \mathrm{~h}$ before measuring proliferation rate in oxidative stress-damaged and normal BMEC. $* P<0.05,{ }^{* *} P<0.01$ compared with the control group. Error bars indicate SEM. SCR-siRNA = scrambled-siRNA. 

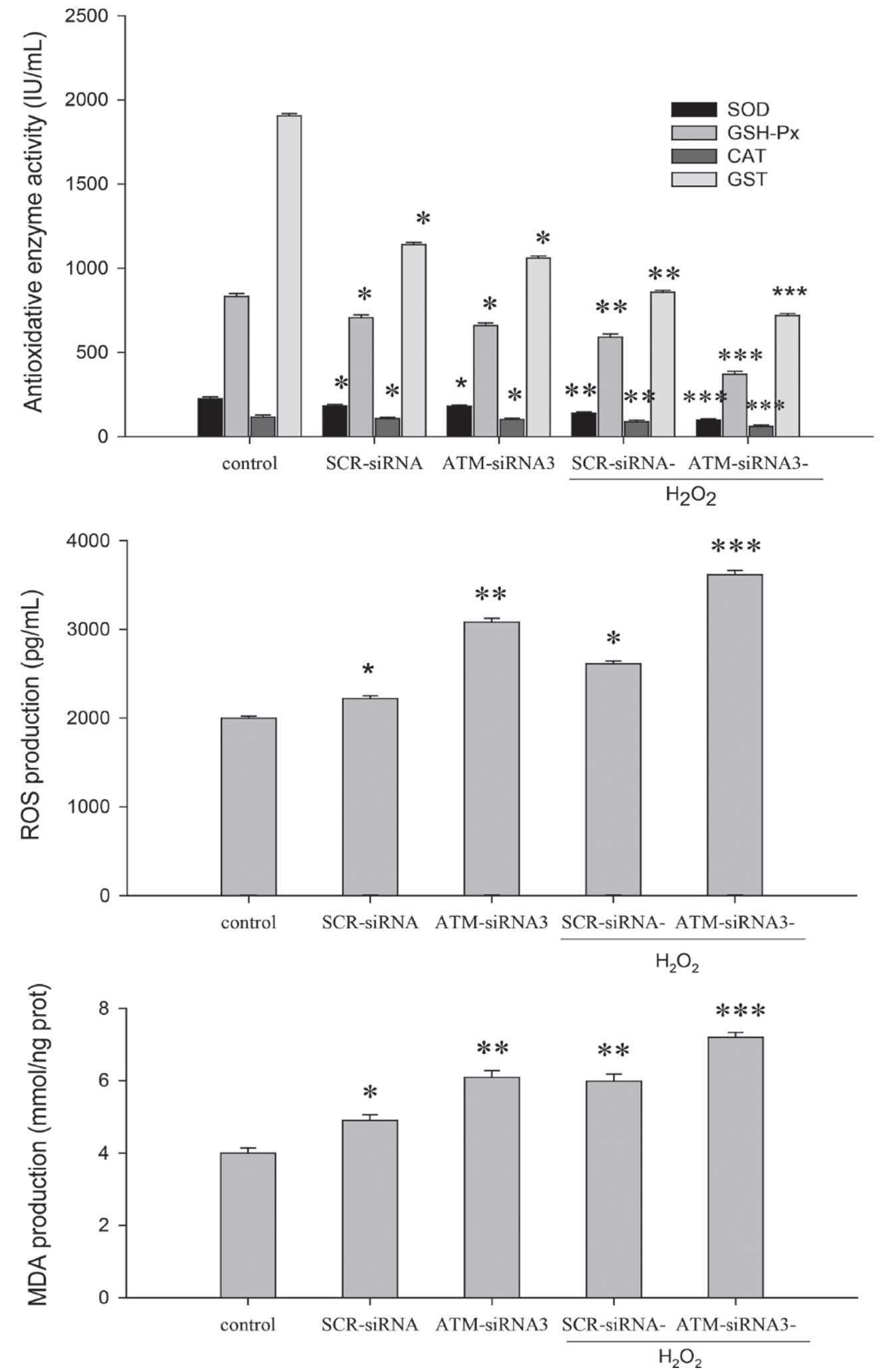

Figure 3. Effect of ataxia telangiectasia-mutated (ATM) on antioxidative enzyme activity in cultured bovine mammary epithelial cells (BMEC). Cells were cultured with $\mathrm{H}_{2} \mathrm{O}_{2}(600 \mu M)$ for $6 \mathrm{~h}$, followed by scrambled-small interfering RNA (siRNA) and ATM-siRNA3 transfection for $48 \mathrm{~h}$ before measuring superoxide dismutase (SOD), glutathione peroxidase (GSH-Px), catalase (CAT), and glutathione-S-transferase (GST) activity, and reactive oxygen species (ROS) and malondialdehyde (MDA) production in oxidative stress-damaged and normal BMEC. ${ }^{*} P<0.05$, ${ }^{* *} P<0.01$ compared with the control group. Error bars indicate SEM. SCR-siRNA = scrambled-siRNA. 
ing BMEC from $\mathrm{H}_{2} \mathrm{O}_{2}$-induced oxidative stress in the NFE2L2-ARE pathway.

\section{Impaired NFE2L2 Transcriptional Activity in the NFE2L2-ARE Pathway}

The normal BMEC and the oxidative-damaged BMEC were transiently transfected with an ARE-luciferase reporter plasmid (pGL3-ARE) and a Renilla luciferase reporter plasmid (pRLtk) followed by treatment with
$600 \mu M \mathrm{H}_{2} \mathrm{O}_{2}$ for $0,6,12$, and $24 \mathrm{~h}$ before the luciferase activity was measured (Figure 6). The results showed that treatment with $\mathrm{H}_{2} \mathrm{O}_{2}$ increased $(P<0.05)$ the transcriptional activity of NFE2L2 in a time-dependent manner in both normal and oxidative-damaged groups. In contrast, in the presence of $\mathrm{H}_{2} \mathrm{O}_{2}$, ARE luciferase activity of oxidative-damaged BMEC was much lower $(P<0.05)$ than normal BMEC. These data clearly indicate that NFE2L2-driven transcriptional activation of ARE is aberrant in oxidative-damaged BMEC.
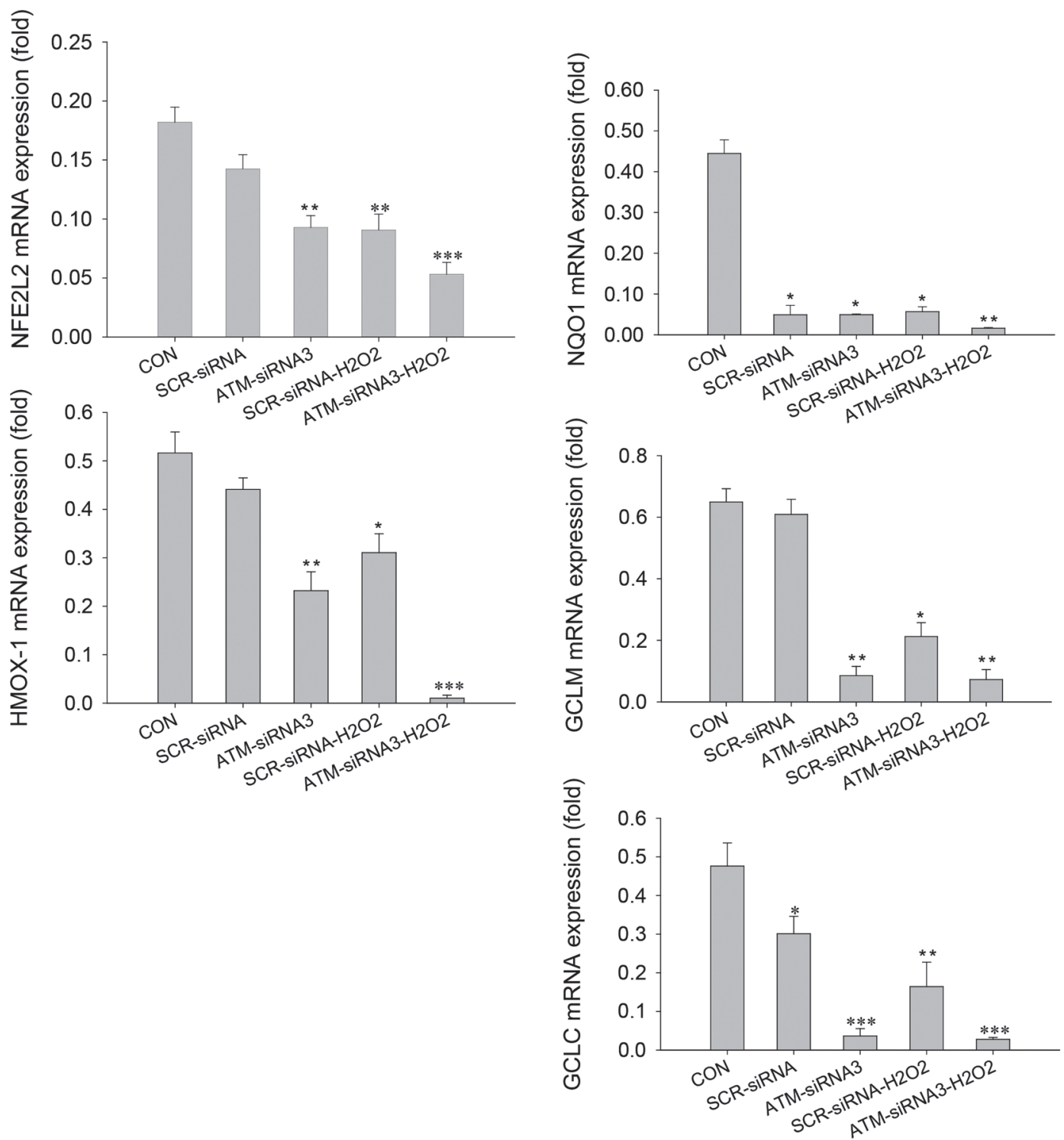

Figure 4. Effects of ataxia telangiectasia-mutated (ATM)-small interfering RNA (siRNA) on downstream expression of genes associated with the nuclear factor erythroid 2-related factor 2-antioxidant response element (ARE) signaling pathway in cultured bovine mammary epithelial cells (BMEC). Cells were cultured with $\mathrm{H}_{2} \mathrm{O}_{2}(600 \mu M)$ for $6 \mathrm{~h}$, followed by scrambled-siRNA and ATM-siRNA3 transfection for $48 \mathrm{~h}$ before measuring the mRNA expression of nuclear factor erythroid 2-related factor 2 (NFE2L2), heme oxygenase-1 (HMOX-1), NADH quinone oxidoreductase 1 (NQO1), glutamyl cystine ligase modulatory subunit (GCLM), and glutamate-cysteine ligase catalytic subunit (GCLC) in oxidative stress-damaged and normal BMEC. CON $=$ control. ${ }^{*} P<0.05$, ${ }^{* *} P<0.01,{ }^{*} * *<0.001$ compared with the control group. Error bars indicate SEM. SCR-siRNA = scrambled-siRNA. 


\section{DISCUSSION}

Several studies in nonruminant cells indicate that excess production of ROS when endogenously or exogenously produced ROS exceed cellular antioxidant defenses may cause oxidative damage (Jena, 2012). Oxidative stress leads to induction of lipid peroxidation and protein modifications followed by cellular dysfunction and disease (Deng et al., 2017). It is well established that oxidative stress is related to the health status of the udder and mammary secretory cell number (Rainard et al., 2013; Thompson-Crispi et al., 2014). A recent study revealed that oxidative stress causes impaired function of BMEC (Jin et al., 2016), with the NFE2L2-ARE pathway apparently playing an important role in the cell's defense mechanisms against oxidative stress. Therefore, the NFE2L2-ARE pathway and its downstream genes may protect BMEC from $\mathrm{H}_{2} \mathrm{O}_{2}$-induced oxidative damage.

The protein NFE2L2 is a redox-sensitive transcription factor that can regulate the expression of several cytoprotective genes (Tang et al., 2011). At least in nonruminants, the ARE pathway controlled by NFE2L2 is one of the main regulators of redox signaling. Activation of ARE stimulates the production of phase II detoxifying enzymes with antioxidant properties that
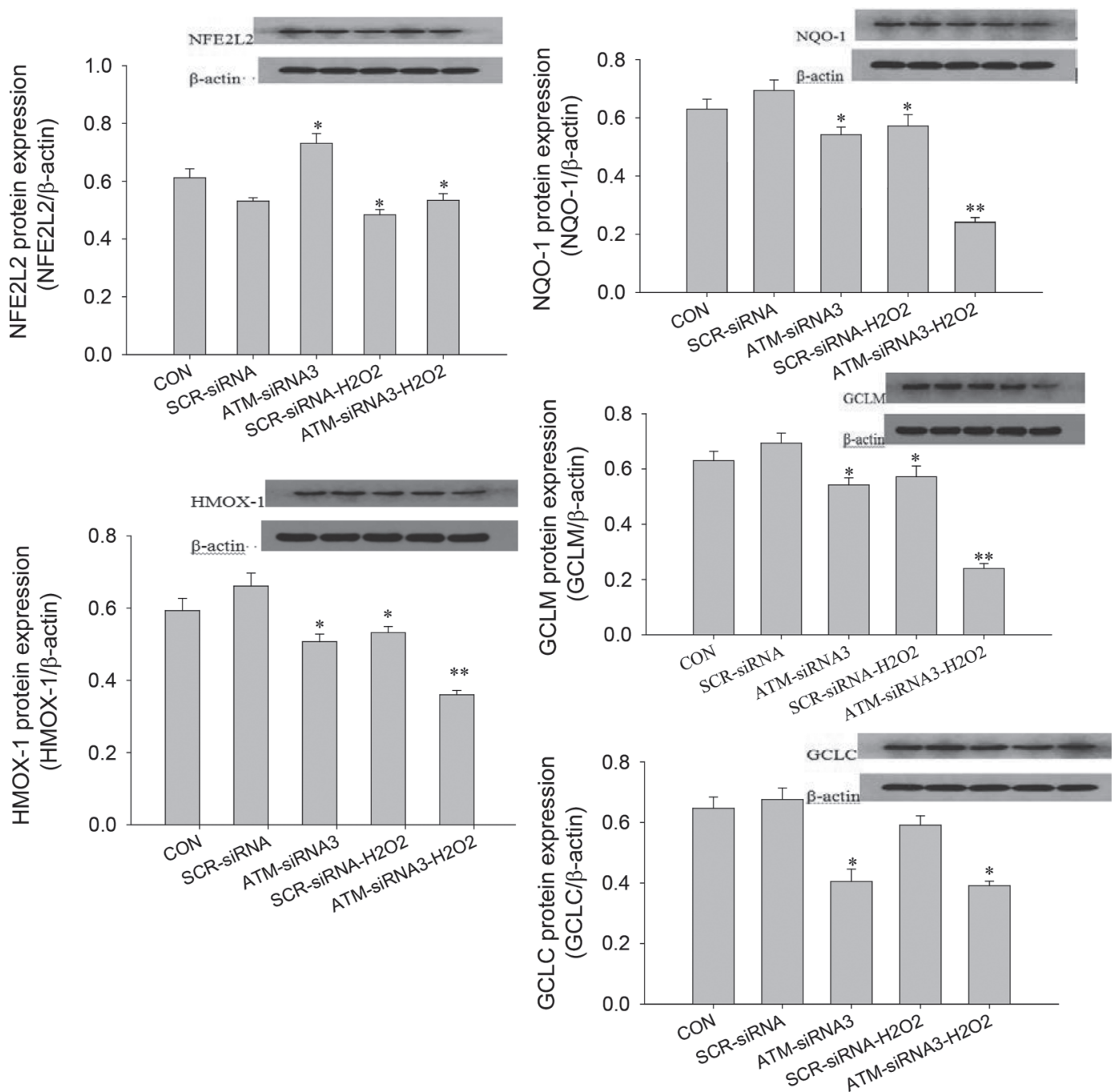

Figure 5. Effects of ataxia telangiectasia-mutated (ATM)-small interfering RNA (siRNA) on downstream expression of genes associated with the nuclear factor erythroid 2-related factor 2-antioxidant response element (ARE) signaling pathway in cultured bovine mammary epithelial cells (BMEC). Cells were cultured with $\mathrm{H}_{2} \mathrm{O}_{2}(600 \mu M)$ for $6 \mathrm{~h}$, followed by scrambled-siRNA and ATM-siRNA3 transfection for 48 h before measuring the protein expression of nuclear factor erythroid 2-related factor 2 (NFE2L2), heme oxygenase-1 (HMOX-1), NADH quinone oxidoreductase 1 (NQO1), glutamyl cystine ligase modulatory subunit (GCLM), and glutamate-cysteine ligase catalytic subunit (GCLC) in oxidative stress-damaged and normal BMEC. CON $=$ control. ${ }^{*} P<0.05,{ }^{* *} P<0.01$ compared with the control group. Error bars indicate SEM. SCRsiRNA $=$ scrambled-siRNA. 


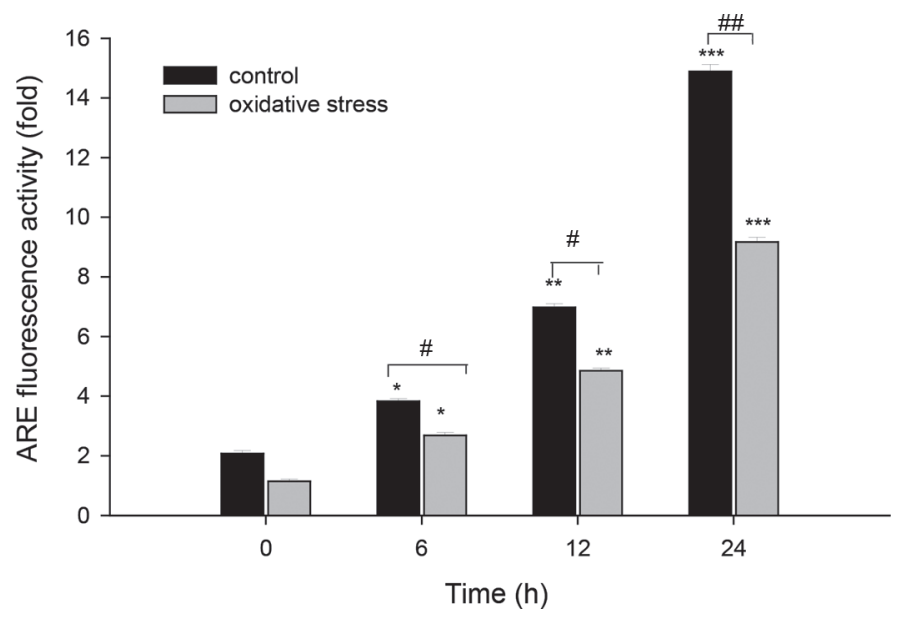

Figure 6. Fluorescence activity of the antioxidant response element (ARE) in control and oxidative stress bovine mammary epithelial cells. Fluorescence activity of ARE in the control and oxidative stress cells was detected with the Biluciferase gene reporter assay after treatment of cells with $\mathrm{H}_{2} \mathrm{O}_{2}(600 \mu M)$ for $0,6,12$, or $24 \mathrm{~h}$. \#P<0.05, \#\#P< 0.01 compared with the control; ${ }^{*} P<0.05$, ${ }^{*}{ }^{*} P<0.01$, and $* * * P<$ 0.001 compared with 0 h. Error bars indicate SEM.

protect cells from oxidative damage (Johnson et al., 2008). The NFE2L2-ARE signaling pathway is a vital regulator of oxidative damage and inflammation, both of which are involved in various types of pathologies in various organs including the mammary gland (Chen et al., 2011; Jian et al., 2011).

In the current study, we identified the potential phosphorylation sites on NFE2L2 through in silico analysis, and found that ATM serine/threonine kinase is a key kinase responsible for the phosphorylation of NFE2L2. Furthermore, we demonstrated that inhibition of ATM activity or ATM silencing can cause marked alterations in oxidative stress leading to decreased BMEC proliferation rate and cell death. Thus, $\mathrm{H}_{2} \mathrm{O}_{2}$-induced cytotoxicity diminishes the capacity of BMEC to cope with this type of stress. This evidence seems to support ATM serine/threonine kinase as a physiologically relevant NFE2L2 kinase.

The ATM serine/threonine kinase protein is activated by breaks in DNA or chromatin induced during meiosis or oxidation (Lavin, 2008). In nonruminants under physiological conditions, ATM mediates the activation of multiple signal transduction pathways (Brown et al., 1999). The protein is primarily localized to the nucleus as a catalytically inactive homodimer (Elson et al., 1996). Once activated, ATM phosphorylates serine/threonine-glutamine (S/T-Q) motifs on more than 700 protein substrates (Brown et al., 1999). Indeed, a recent large-scale phosphoproteomics screen identified cytoplasmic ATM activation in response to oxidative stress with over 2,500 unique protein targets (Kozlov et al., 2016). The lower ARE luciferase activity in response to $\mathrm{H}_{2} \mathrm{O}_{2}$ stimulus strongly suggested that the NFE2L2-ARE pathway is dysfunctional when a supraphysiological concentration of $\mathrm{H}_{2} \mathrm{O}_{2}$ is produced in BMEC.

The antioxidant enzymes SOD, GSH-Px, CAT, and GST can scavenge ROS to prevent cell damage, and numerous reports from research with nonruminant systems have confirmed that NFE2L2 plays a crucial role in eliciting adaptive responses to diverse stresses by upregulating these enzymes (Miranda et al., 2011), all of which helps restore cellular redox status (Son et al., 2010; Magesh et al., 2012; Tsou et al., 2015). Therefore, activation of the NFE2L2-ARE pathway might potentially be a new target in the treatment of oxidative stress in the dairy cow mammary gland (Loor et al., 2013). In this study, we confirmed that silencing ATM increased ROS and MDA concentrations when challenging with a supraphysiological dose of $\mathrm{H}_{2} \mathrm{O}_{2}$ because of a decrease in antioxidant enzyme activity. Thus, the data support the role of ATM in the antioxidant response of BMEC, which is in accordance with previous reports in nonruminant cells (Kamsler et al., 2001; Perry and Tainer, 2011).

Among the known antioxidant enzymes, HMOX-1 is an inducible antioxidant enzyme and protects cells against oxidative stress. Expression of HMOX-1 is triggered by diverse stressors including UV radiation, hypoxia, inflammation, $\mathrm{H}_{2} \mathrm{O}_{2}$, and nitric oxide (Motterlini, 2000; Naughton et al., 2002). The decrease in antioxidative enzyme activity, protein, and mRNA expression level of NFE2L2, HMOX-1, NOQ1, GCLC, and GCLM, along with the increased concentration of ROS and MDA in response to supraphysiological treatment with $\mathrm{H}_{2} \mathrm{O}_{2}$ when ATM was silenced, provided a strong indication that ATM kinase plays an important role in the NFE2L2-ARE signaling pathway. Thus, as demonstrated in vitro (Matsuda, 2014; Biagiotti et al., 2016) and in vivo (Matsuda, 2014) in nonruminant cells, manipulating ATM kinase activity might be a useful strategy for controlling oxidative stress.

Clearly, our data provide evidence that oxidative stress in response to a supraphysiological dose of $\mathrm{H}_{2} \mathrm{O}_{2}$ decreases NFE2L2-driven transcriptional activation of ARE in BMEC. The abnormal expression of ATM kinase is one key factor preventing NFE2L2 phosphorylation and nuclear activity. The exact mechanisms that control ATM expression remain unclear, but the present data offer support for ATM kinase as a novel target to help regulate or control activity of the NFE2L2-ARE pathway under oxidative stress. 


\section{CONCLUSIONS}

Abnormal expression and activation of ATM serine/ threonine kinase during oxidative stress compromises NFE2L2 activation, leading to lower antioxidative enzyme activity and expression of antioxidant genes. As such, cellular proliferation rates are decreased. Further studies should focus on the regulation of ATM serine/ threonine kinase.

\section{ACKNOWLEDGMENTS}

This research was supported by grants from National Natural Science Foundation of China (Beijing, no. 31460616 and no. 31601975) and from the China Agriculture Research System (no. CARS-36, Beijing). Y. Ma received a China Scholarship Council (Beijing) postdoctoral fellowship to train at the University of Illinois (Urbana).

\section{REFERENCES}

Biagiotti, S., M. Menotta, S. Orazi, C. Spapperi, S. Brundu, A. Fraternale, M. Bianchi, L. Rossi, L. Chessa, and M. Magnani. 2016. Dexamethasone improves redox state in ataxia telangiectasia cells by promoting an NRF2-mediated antioxidant response. FEBS J. 283:3962-3978.

Blom, N., S. Gammeltoft, and S. Brunak. 1999. Sequence and structure-based prediction of eukaryotic protein phosphorylation sites. J. Mol. Biol. 294:1351-1362.

Blom, N., T. Sicheritz-Ponten, R. Gupta, S. Gammeltoft, and S. Brunak. 2004. Prediction of post-translational glycosylation and phosphorylation of proteins from the amino acid sequence. Proteomics 4:1633-1649.

Brown, K. D., C. Barlow, and A. Wynshaw-Boris. 1999. Multiple ATM-dependent pathways: An explanation for pleiotropy. Am. J. Hum. Genet. 64:46-50.

Burdon, R. H. 1995. Superoxide and hydrogen peroxide in relation to mammalian cell proliferation. Free Radic. Biol. Med. 18:775-794.

Chen, G., Q. Fang, J. Zhang, D. Zhou, and Z. Wang. 2011. Role of the Nrf2-ARE pathway in early brain injury after experimental subarachnoid hemorrhage. J. Neurosci. Res. 89:515-523.

Dasari, A., J. N. Bartholomew, D. Volonte, and F. Galbiati. 2006. Oxidative stress induces premature senescence by stimulating caveolin-1 gene transcription through p38 mitogen-activated protein kinase/Sp1-mediated activation of two GC-rich promoter elements. Cancer Res. 66:10805-10814.

Deng, S., K. Yu, W. Jiang, Y. Li, S. Wang, Z. Deng, Y. Yao, B. Zhang, G. Liu, Y. Liu, and Z. Lian. 2017. Over-expression of Toll-like receptor 2 up-regulates heme oxygenase-1 expression and decreases oxidative injury in dairy goats. J. Anim. Sci. Biotechnol. 8:3.

Dinkova-Kostova, A. T., W. D. Holtzclaw, R. N. Cole, K. Itoh, N. Wakabayashi, Y. Katoh, M. Yamamoto, and P. Talalay. 2002. Direct evidence that sulfhydryl groups of Keap1 are the sensors regulating induction of phase 2 enzymes that protect against carcinogens and oxidants. Proc. Natl. Acad. Sci. USA 99:11908-11913.

Elson, A., Y. Wang, C. J. Daugherty, C. C. Morton, F. Zhou, J. Campos-Torres, and P. Leder. 1996. Pleiotropic defects in ataxiatelangiectasia protein-deficient mice. Proc. Natl. Acad. Sci. USA 93:13084-13089.

Hayes, J. D., and M. McMahon. 2001. Molecular basis for the contribution of the antioxidant responsive element to cancer chemoprevention. Cancer Lett. 174:103-113.
Itoh, K., N. Wakabayashi, Y. Katoh, T. Ishii, K. Igarashi, J. D. Engel, and M. Yamamoto. 1999. Keap1 represses nuclear activation of antioxidant responsive elements by Nrf2 through binding to the amino-terminal Neh2 domain. Genes Dev. 13:76-86.

Jena, N. R. 2012. DNA damage by reactive species: Mechanisms, mutation and repair. J. Biosci. 37:503-517.

Jian, Z., K. Li, L. Liu, Y. Zhang, Z. Zhou, C. Li, and T. Gao. 2011. Heme oxygenase-1 protects human melanocytes from $\mathrm{H} 2 \mathrm{O} 2$-induced oxidative stress via the Nrf2-ARE pathway. J. Invest. Dermatol. 131:1420-1427.

Jin, X., K. Wang, H. Liu, F. Hu, F. Zhao, and J. Liu. 2016. Protection of bovine mammary epithelial cells from hydrogen peroxideinduced oxidative cell damage by resveratrol. Oxid. Med. Cell. Longev. 2016:2572175.

Johnson, J. A., D. A. Johnson, A. D. Kraft, M. J. Calkins, R. J. Jakel, M. R. Vargas, and P. C. Chen. 2008. The Nrf2-ARE pathway: An indicator and modulator of oxidative stress in neurodegeneration. Ann. N. Y. Acad. Sci. 1147:61-69.

Kamsler, A., D. Daily, A. Hochman, N. Stern, Y. Shiloh, G. Rotman, and A. Barzilai. 2001. Increased oxidative stress in ataxia telangiectasia evidenced by alterations in redox state of brains from Atm-deficient mice. Cancer Res. 61:1849-1854.

Kensler, T. W., N. Wakabayashi, and S. Biswal. 2007. Cell survival responses to environmental stresses via the Keap1-Nrf2-ARE pathway. Annu. Rev. Pharmacol. Toxicol. 47:89-116.

Klaunig, J. E., L. M. Kamendulis, and B. A. Hocevar. 2010. Oxidative stress and oxidative damage in carcinogenesis. Toxicol. Pathol. 38:96-109.

Kozlov, S. V., A. J. Waardenberg, K. Engholm-Keller, J. W. Arthur, M. E. Graham, and M. Lavin. 2016. Reactive oxygen species (ROS)-activated ATM-dependent phosphorylation of cytoplasmic substrates identified by large-scale phosphoproteomics screen. Mol. Cell. Proteomics 15:1032-1047.

Lavin, M. F. 2008. Ataxia-telangiectasia: From a rare disorder to a paradigm for cell signalling and cancer. Nat. Rev. Mol. Cell Biol. 9:759-769.

Lee, M. Y., and K. K. Griendling. 2008. Redox signaling, vascular function, and hypertension. Antioxid. Redox Signal. 10:1045-1059.

Livak, K. J., and T. D. Schmittgen. 2001. Analysis of relative gene expression data using real-time quantitative PCR and the 2(-Delta Delta C(T)) method. Methods 25:402-408.

Loor, J. J., M. Bionaz, and J. K. Drackley. 2013. Systems physiology in dairy cattle: Nutritional genomics and beyond. Annu. Rev. Anim. Biosci. 2013:365-392. https://doi.org/10.1146/annurev -animal-031412-103728.

Magesh, S., Y. Chen, and L. Hu. 2012. Small molecule modulators of Keap1-Nrf2-ARE pathway as potential preventive and therapeutic agents. Med. Res. Rev. 32:687-726.

Matsuda, Y., A. Sanpei, T. Wakai, M. Kubota, M. Osawa, Y. Hirose, J. Sakata, T. Kobayashi, S. Fujimaki, M. Takamura, S. Yamagiwa, M. Yano, S. Ohkoshi, and Y. Aoyagi. 2014. Hepatitis B virus X stimulates redox signaling through activation of ataxia telangiectasia mutated kinase. Int. J. Clin. Exp. Pathol. 7:2032-2043.

Miranda, S. G., N. G. Purdie, V. R. Osborne, B. L. Coomber, and J. P. Cant. 2011. Selenomethionine increases proliferation and reduces apoptosis in bovine mammary epithelial cells under oxidative stress. J. Dairy Sci. 94:165-173.

Mori, K., M. Shibanuma, and K. Nose. 2004. Invasive potential induced under long-term oxidative stress in mammary epithelial cells. Cancer Res. 64:7464-7472.

Motterlini, R. F., R. Bassi, V. Calabrese, J. E. Clark, and C. J. Green. 2000. Endothelial heme oxygenase-1 induction by hypoxia. J. Biol. Chem. 275:13613-13620.

Naughton, P., R. Foresti, S. K. Bains, M. Hoque, C. J. Green, and R. Motterlini. 2002. Induction of heme oxygenase 1 by nitrosative stress. A role for nitroxyl anion. J. Biol. Chem. 277:40666-40674.

Niture, S. K., R. Khatri, and A. K. Jaiswal. 2014. Regulation of Nrf2An update. Free Radic. Biol. Med. 66:36-44.

Perry, J. J. P., and J. A. Tainer. 2011. All stressed out without ATM kinase. Sci. Signal. 4:pe18. 
Rainard, P., P. Cunha, S. Bougarn, A. Fromageau, C. Rossignol, F. B. Gilbert, and P. Berthon. 2013. T helper 17-associated cytokines are produced during antigen-specific inflammation in the mammary gland. PLoS One 8:e63471.

Son, T. G., S. Camandola, T. V. Arumugam, R. G. Cutler, R. S. Telljohann, M. R. Mughal, T. A. Moore, W. Luo, Q. S. Yu, D. A. Johnson, J. A. Johnson, N. H. Greig, and M. P. Mattson. 2010. Plumbagin, a novel Nrf2/ARE activator, protects against cerebral ischemia. J. Neurochem. 112:1316-1326.

Tang, X., H. Wang, L. Fan, X. Wu, A. Xin, H. Ren, and X. J. Wang. 2011. Luteolin inhibits Nrf2 leading to negative regulation of the Nrf2/ARE pathway and sensitization of human lung carcinoma A549 cells to therapeutic drugs. Free Radic. Biol. Med. 50:15991609 .

Thompson-Crispi, K., H. Atalla, F. Miglior, and B. A. Mallard. 2014 Bovine mastitis: Frontiers in immunogenetics. Front. Immunol. $5: 493$
Tong, K. I., Y. Katoh, H. Kusunoki, K. Itoh, T. Tanaka, and M. Yamamoto. 2006. Keap1 recruits Neh2 through binding to ETGE and DLG motifs: Characterization of the two-site molecular recognition model. Mol. Cell. Biol. 26:2887-2900.

Tsou, Y. H., C. T. Shih, C. H. Ching, J. Y. Huang, C. J. Jen, L. Yu, Y. M. Kuo, F. S. Wu, and J. I. Chuang. 2015. Treadmill exercise activates Nrf2 antioxidant system to protect the nigrostriatal dopaminergic neurons from MPP+ toxicity. Exp. Neurol. 263:50-62.

Zhu, H., K. Itoh, M. Yamamoto, J. L. Zweier, and Y. Li. 2005. Role of Nrf2 signaling in regulation of antioxidants and phase 2 enzymes in cardiac fibroblasts: Protection against reactive oxygen and nitrogen species-induced cell injury. FEBS Lett. 579:3029-3036. 